\title{
Aa. Vv., éd. Luc Fraisse, avec la collaboration de Gilbert Schrenck et Michel Stanesco, Tradition et modernité en littérature
}

\section{Lise Sabourin}

\section{(2) OpenEdition Journals \\ Édition électronique \\ URL : http://journals.openedition.org/studifrancesi/6323 \\ DOI : 10.4000/studifrancesi.6323 \\ ISSN : 2421-5856 \\ Éditeur \\ Rosenberg \& Sellier}

\section{Édition imprimée}

Date de publication : 1 novembre 2010

Pagination : 562

ISSN : 0039-2944

\section{Référence électronique}

Lise Sabourin, «Aa. Vv., éd. Luc Fraisse, avec la collaboration de Gilbert Schrenck et Michel Stanesco, Tradition et modernité en littérature », Studi Francesi [En ligne], 162 (LIV | III) | 2010, mis en ligne le 30 novembre 2015, consulté le 07 janvier 2021. URL : http://journals.openedition.org/studifrancesi/6323 ; DOI : https://doi.org/10.4000/studifrancesi.6323

Ce document a été généré automatiquement le 7 janvier 2021.

\section{cc) (†) $\odot$}

Studi Francesi è distribuita con Licenza Creative Commons Attribuzione - Non commerciale - Non opere derivate 4.0 Internazionale. 


\title{
Aa. Vv., éd. Luc Fraisse, avec la collaboration de Gilbert Schrenck et Michel Stanesco, Tradition et modernité en littérature
}

\author{
Lise Sabourin
}

\section{RÉFÉRENCE}

AA. VV., éd. Luc FRAISSE, avec la collaboration de Gilbert SCHRENCK et Michel STANESCO, Tradition et modernité en littérature, Université de Haute Alsace, Institut de recherche en langues et littératures européennes, Paris, Éditions Orizons, «Universités. Domaine littéraire», 2009, pp. 381.

1 Dans ce volume réuni par Luc Fraisse, quatre contributions touchent la période 1800-1850.

2 Tout d'abord, par la lecture de Chénier, généralisée seulement dans la décennie de 1820. Éric FRANCALANZA cherche dans les soubassements esthétiques de L'Invention de Chénier, écrit en 1790, «une poétique d'inspiration maçonnique» (pp. 155-174): en effet, la référence sculpturale y renvoie au souhait de "grandeur tranquille» des Lumières, mais aussi à la pratique par les sociétés secrètes de l'allégorie comme figure moderne de la création. Or, comme une réponse au défi de ce poème, Sainte-Beuve propose à la génération romantique «la renaissance du sonnet au XIX siècle». Daniel SIPE s'interroge sur cette modulation des conseils de Chénier: «sur des vers nouveaux, faisons des vers achroniques?» (pp. 207-224). L'héritage de Du Bellay offrait une contrainte formelle provocante, mais aussi une fluidité de sujets. Effectivement, dès Nerval qui l'onirise, puis Gautier qui cherche dans son histoire une épuration esthétique, puis chez Baudelaire et les symbolistes, cet archétype a priori rigide se révèle porteur d'innovations: méditation sur les signes de l'écriture concise, «monade poétique» 
d'unité visuelle et métrique (p. 211) propice à l'analogie universelle, méfiance envers le lyrisme amoureux favorable au surgissement des thématiques de la modernité.

3 Puis deux articles réfléchissent sur la relation à l'héritage romanesque au seuil de la rénovation romantique. Olivier LARIZZA examine la place de Melmoth l'homme errant (1820) de Maturin (pp. 175-190) au point d'orgue de la tradition du roman gothique depuis 1765: la synthèse qu'il y opère, élevant au niveau métaphysique ses motifs violents, a fait son insuccès immédiat, mais son statut référentiel ultérieur. Sébastien BAUDOIN retrouve dans «la description de Chateaubriand» les souvenirs de la pratique de l'ut pictura poesis revue par l'émergence du moi romantique (pp. 191-206): le prosateur peintre s'affranchit en effet de la mimesis pour dissoudre le paysage, par un travail «d'après nature», en tableaux propices à la méditation et à l'introspection. 